\section{Seasonal onychomadesis in an elderly gentleman}

\author{
Supriya S. Venugopal, ${ }^{1,2}$ Dedee F. Murrell ${ }^{1,2}$ \\ 'Department of Dermatology, St George \\ Hospital, Sydney; ' University of NSW \\ Sydney
}

\section{Abstract}

A 79-year-old man with a history of dementia and hypertension initially presented with a ten year history of Beau's lines and seasonal nail shedding of his fingernails only. $\mathrm{He}$ denied any exposure to heavy metals, unusual activities or food. He stated that the seasonal nail shedding had been occurring for the last 5-10 years. On examination, six out of ten fingernails had been affected. He had significant toenail dystrophy. Fungal cultures and PAS staining of the toenails were negative. Routine serum biochemistry and haematology results were normal. Serum arsenic, cadmium and lead levels were also normal. Vitamin B12, zinc, folate, iron studies, thyroid function studies and homocysteine levels were also normal. Rheumatoid factor and anti-cyclic citrullinated peptide antibody antibodies were negative. Bilateral hand X-ray showed osteoarthritic change and did not show any features of psoriatic arthropathy. We discuss the case of a 79-year-old man with seasonal nail shedding, curiously affecting his fingernails only.

\section{Introduction}

A 79-year-old Caucasian gentleman presented with a ten year history of fingernail and toenail nail dystrophy and fingernails that 'broke off' once a year, usually in winter. He had a background history of hypertension and mild dementia and much of the history came from his sons, who helped to take care of him. These episodes of nail shedding were asymptomatic, with no history of preceding illnesses or symptoms.

\section{Materials and Methods}

A thorough history and examination was taken and performed. The patient had several haematological and radiological investigations performed to exclude a sinister cause for the nail shedding. There was no contact with chemicals or heavy metals or ingestion of any chemicals, in particular lead or arsenic. His regular medications included atenolol and ramipril for over ten years. He denied use of any over the counter or herbal medications. He had no known allergies. There was no family history of nail disorders or seasonal shedding of nails. There was a family history of type 2 diabetes mellitus and no other dermatological conditions were present. He denied any physical or emotional stress and any previous psychiatric history. The patient had received the vaxigrip influenza and pneumovax 23 vaccine in May and June 2007, respectively. He was reviewed in September 2007, four months after the first vaccination. He did not receive these vaccines regularly. Other than these two vaccinations, there were no new medications or changes to his medication regime.

On examination in 2007 there were Beau's lines of all the fingernails with the distal nail plate intact (Figure 1). There were no other fingernail findings such as discolouration, subungual haemorrhages, hyperkeratosis, onycholysis or signs of paronychia. There was, however, significant toenail dystrophy. There was no web space scaling in the toes or the hands. There was no evidence of dermatological pathology on examination of his skin and mucosal surfaces. During this initial visit, the provisional diagnosis was exposure to toxins resulting in Beau's lines in the fingernails or onychomycosis. Toenail clippings were sent for microscopy, fungal culture and Periodic AcidShiff (PAS) examination.

\section{Results}

Routine blood tests included full blood count, urea, electrolytes, creatinine, liver function tests, serum folate and vitamin B12, iron studies, homocysteine levels and thyroid function. The routine blood tests were normal. Microscopic investigation of the toenail clippings revealed no fungal elements and PAS staining was negative. Toenail fungal culture was also negative. The patient returned for follow up two months later and reported the asymptomatic loss of six of his ten fingernails. He repeatedly denied ingesting chemicals or being exposed to heavy metals. General systems review also revealed no relevant positive findings. During his second visit, there was marked improvement of his toenail dystrophy, despite any treatment was commenced. Beau's lines were still present on his remaining fingernails (Figure 2). There were no other relevant findings on general examination. The patient subsequently returned for review in August of 2008 and Beau's lines were still present on his finger nails (Figure 3). Furthermore, his fingernails appeared to have commenced shedding. The patient was subsequently investigated for arsenic, lead or cadmium toxicity. Serum arsenic, lead, cadmium levels and repeat full blood count (FBC),
Correspondence: Dedee F. Murrell, Department of Dermatology St George Hospital, Kogarah Sydney, NSW, Australia. E-mail: d.murrell@unsw.edu.au

Key words: seasonal, onychomadesis.

Acknowledgements: the authors thank the patient and his sons for their co-operation with investigations and history.

Received for publication: 30 October 2009.

Revision received: 6 December 2009.

Accepted for publication: 9 December 2009.

This work is licensed under a Creative Commons Attribution 3.0 License (by-nc 3.0).

○C Copyright S.S. Venugopal, D.F. Murrell, 2009

Licensee PAGEPress, Italy

Dermatology Reports 2009; 1:e3

doi:10.4081/dr.2009.e3

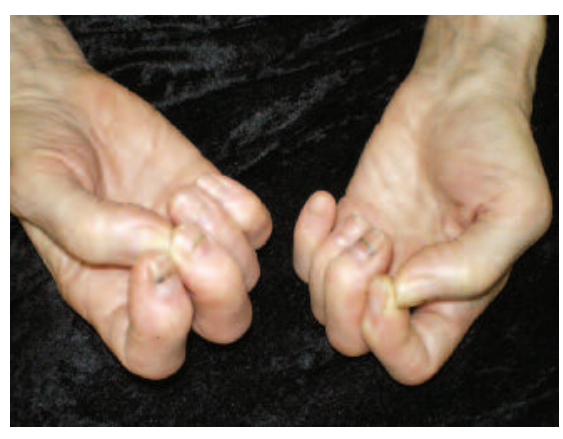

Figure 1. Beau's lines.

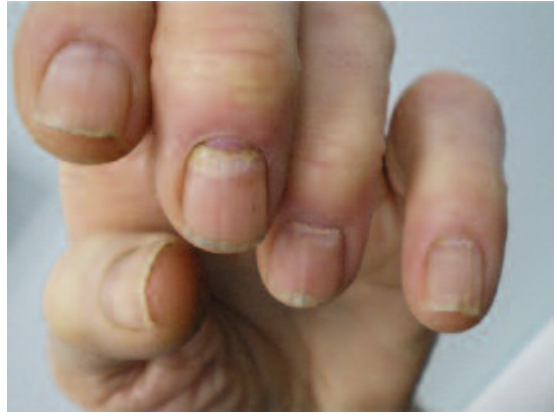

Figure 2. Fingernail onychomadesis in September 2007.

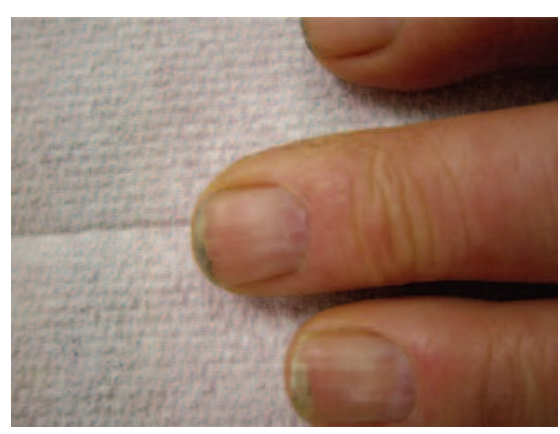

Figure 3. Fingernail onychomadesis in August 2008. 
eletrolytes urea and creatinine (EUC ) and liver function tests (LFTs) were normal. The initial differential of onychomycosis was rejected as toenail fungal culture and PAS staining was negative. The provisional diagnosis was that of seasonal nail shedding and the patient was commenced on vitamin $\mathrm{D}$, calcium, zinc and folate supplementation after the first consultation, due to suspicion that he may be deficient even if his blood tests did not reveal any deficiencies.

The patient was noted to have Beau's lines and onychomadesis of all fingernails and periodic nail shedding during the winter months over a two-year period. All toenails appeared thickened and dystrophic.

This case highlights an interesting seasonal phenomenon of onychomadesis of predominantly fingernails in an elderly, demented gentleman. A definite cause could not be elucidated in this case.

\section{Discussion}

In 1846, Beau ${ }^{1}$ first described transverse grooves in the nail plates of patients suffering with typhoid fever and several other severe systemic conditions. Beau's lines are transverse ridged grooves found on fingernails and may be secondary to trauma, drugs, such as chemotherapy agents, severe systemic disease, zinc deficiency, carpal tunnel syndrome, dermatitis of the skin directly adjacent to the nail or malnutrition. ${ }^{2}$ The transient and complete inhibition of nail growth for at least one to two weeks results in Beau's lines. ${ }^{3}$ Onychomadesis is characterized by cleavage under the proximal portion of the nail proceeded by disappearance of the juxtamatricial portion of the nail surface. ${ }^{3}$ In latent onychomadesis, Beau's lines are apparent on the nail surface and become visible several weeks after the onset of the causative systemic disease.

Nail shedding may occur with or without scarring. Nail loss without scarring is usually due to trauma such as nail biting. Scarring nail loss may be due to tumours or erosive lichen planus or severe systemic disease. ${ }^{4}$

Onychomadesis may be secondary to a number of causes including severe systemic illnesses, bullous dermatoses such as epidermolysis bullosa, adverse drug reactions, particularly to chemotherapeutic agents, ${ }^{5}$ acute paronychia or severe stress. ${ }^{3,6}$ Onychomadesis may be inherited in an autosomal dominant form and is associated with periodic shedding, but the majority of cases are idiopathic. In cases of latent onychomadesis, a complete and transient inhibition of nail growth results in Beau's lines. ${ }^{3,7,8}$

Nail shedding associated with Kawasaki syndrome, ${ }^{9}$ severe alopecia areata, hand-foot and mouth disease, ${ }^{3}$ cutaneous T-cell lymphoma, ${ }^{10}$ severe psychological stress, intensive X-ray therapy, acute paronychia, ${ }^{11,12}$ pyogenic granuloma, ${ }^{13}$ SLE, ${ }^{7}$ keratosis punctata ${ }^{11,12}$ and bullous dermatoses such as pemphigus ${ }^{7,14,15}$ have also been reported. ${ }^{8,16-18}$ In our case no specific cause could be found, but the seasonal nature of his presentation might suggest a viral/infectious aetiology despite the lack of evidence. Periodic nail shedding has also been described in patients with and without a family history of epidermolysis bullosa, ${ }^{19}$ but this patient did not have a family history of epidermolysis bullosa.

This is a case of idiopathic onychomadesis in a gentleman who was diagnosed after ten years that appeared every year in winter, with no apparent cause. Many cases of onychomadesis may be overlooked by physicians as they may not be voiced by the patient or may be simply put down to nail shedding secondary to trauma. Trauma should be considered as a cause of onychomadesis particularly when it is asymmetrical. Patients with periodic nail shedding should be thoroughly investigated for severe systemic illnesses, adverse drug reactions and heavy metal toxicity. A thorough psychosocial history should also be performed to exclude significant stressors.

\section{References}

1. Beau JHS. Note sur certains caracteres de semeilogie retrospective presentes par les ongles. Arch Gen Med 1846;11:447-58.

2. Samman PD. The nails. In: Rook A, Wilkinson DS, Ebling FJG, editors. Textbook of Dermatology. 2nd ed. Boston: Blackwell Scientific Publications 1979; 1825-1855.

3. Bernier V, Labreze C, Bury F, Taieb A. Nail matrix arrest in the course of hand, food and mouth disease. Eur J Pediatr 2001; 160:649-51.
4. Dermnetnz.org. Nail diseases. 2007. Available at: http://www.dermnet.org.nz/ hair-nails-sweat/pdf/naildiseasedermnetnz.pdf [Last accessed on 15 August 2008].

5. Cetin M, Utas S, Unal A, Altinbas M. Shedding of the nails due to chemotherapy (onychomadesis) JEADV 1998;11:193-4.

6. McGrath JA, Ishida-Yamamoto A, Tidman MJ, et al. Epidermolysis Bullosa simplex (Dowling-Meara). A clinicopathological review. Br J Dermatol 1992;126:421-30.

7. Oliver WJ. Recurrent onychoptosis occurring as a familial disorder. Br J Dermatol 1927;39:297-9.

8. Mehra A, Murphy RJ, Wilson BB. Idio-pathic familial onychomadesis. J Am Acad Dermatol 2000;43:349-50.

9. Ciastko AR. Onychomadesis and Kawasaki disease. CMAJ 2002;166:1069.

10. Fleming CJ, Hunt MJ, Barnetson R. Mycosis fungoides with onychomadesis. Br J Dermatol 1996;135:1012.

11. Baran R, Dawber RPR. Diseases of the nail and their management. Oxford: Blackwell Scientific Publications; 1984.

12. Baran R, Dawber P.R, Haneke E, et al. A text atlas of nail disorders. Techniques in investigation and diagnosis. 3rd ed. London: Martin Dunitz; 2003.

13. Tosti A, Piraccini BM, Camacho-Martinez F. Onychomadesis and pyogenic granuloma following cast immobilization. Arch Dermatol 2001;137:231-2.

14. Shafi M, Khatri ML, Mashina M, BenGhazeil M. Pemphigus: A clinical study of 109 cases from Tripoli, Libya. Indian J Dermatol Venereol Leprol 1994;60:140-3.

15. de Berker D, Dalziel K, Dawber RPR, Wojnarowska F. Pemphigus associated with nail dystrophy. Br J Dermatol 2006; 129:461-4.

16. Pilapil VR, Quizon DF. Nail shedding in Kawasaki syndrome. Am J Dis Child 1990; 144:142-3.

17. Tosti A, Morelli R, Bardazzi F, Peluso AM. Prevalence of nail abnormalities in children with alopecia areata. Pediatr Dermatol 1994;11:112-5.

18. Hurwitz S, Disorders of hair and nails. In: Hurwitz S, editor. Clinical pediatric dermatology. Philadelphia:Saunders 1993;507508.

19. Main RA. Periodic shedding of the nails. Br J Dermatol 1973;88:497. 